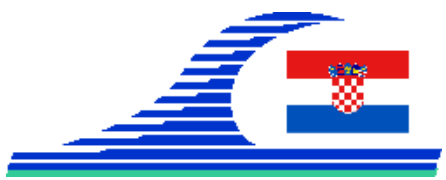

\title{
Climate change - Adaptation options for seaports
}

\section{Baerbel KOPPE ${ }^{1}$}

1. Bremen City University of Applied Sciences, Institute for Hydraulic and Coastal Engineering (IWA), Bremen, Germany.

baerbel.koppe@hs-bremen.de

\begin{abstract}
:
In view of the immense damage potential an understanding and consideration of the expected impacts of future climate change by port planners, port authorities, terminal operators and asset managers allows for considerable long-term cost savings. A threestep approach for determination of the vulnerability of a seaport to climate change is presented as well as examples of climate change adaptation measures in seaports.
\end{abstract}

\section{Keywords:}

Climate change, Vulnerability, Exposure, Sensitivity, Adaptive capacity, Adaptation measures, Port engineering, Maritime structures.

\section{Introduction}

Due to their location at the intersection between sea and land, marine facilities are most vulnerable to changes of all water related parameters like mean relative sea level, storm water levels, wind waves and swell, tidal regime, sedimentation rates, waterborne immigration of species, water salinity and acidity. Furthermore, seaports can be affected directly by temperature, precipitation and wind changes with respect to e.g. cooling system energy demands, terminal pavement durability, storm-water drainage system capacity, empty container storage heights etc.

It is difficult to make general statements on the vulnerability of seaports to climate change. In some cases, already today climate change related problems in seaports are obvious, like changing properties of permafrost soils and related foundation problems in high latitudes. Other climate change impacts will influence port planning and operation only at a later stage, because in short and mid-term only minor effects are effective or the vulnerability of the system 'seaport asset' to the respective climate trend is only marginal. Additionally, ports located at the open sea have to bear other loads than estuary or lock-separated ports and the sensitivity of cargo handling with respect to wind and wave loads differs with cargo type.

Restrictions for assessment and management of climate change challenges to seaports are manifold as it is still difficult to reliably predict climate change effects and to deal 
Mediterranean rocky coasts:

Features, processes, evolution and problems

with the long-time spans climate change refers to. Climate change projections refer to time spans of decades to centuries, because the climate variability makes it difficult to generate any short-term projections of less than 25 years. In contrast, today's port master plans are laid out for a time span of at the most 15 to 25 years, not least because industrial planning horizons seldom exceed 15 years. Therefore, many port planners perceive that impacts of climate change will not strike even their most far-reaching plans. This attitude neglects that already today some climate change effects are observable and that these changes will most probably continue within the next decades and centuries. Furthermore, the planning horizons in ports are generally much shorter than the design life of the port structures.

Differences in planning horizons of port master plans and selected port facilities are demonstrated in Table 1. These numbers show that structures built today have to withstand stresses not only in 20 but also in 60 or even 100 years. Today's port planning and investment decisions will affect how well the infrastructure accommodates the impacts of future climate change.

Table 1: Differences in planning horizons and lifetime of port facilities.

\begin{tabular}{|l|l|l|l|l|l|l|l|l|l|l|}
\hline Port planning / Port super- and infrastructure & \multicolumn{7}{|c|}{ Planning horizon / Lifetime in years } \\
\hline Most common planning horizons of port master plans & $\mathbf{1 0}$ & $\mathbf{2 0}$ & $\mathbf{3 0}$ & $\mathbf{4 0}$ & $\mathbf{5 0}$ & $\mathbf{6 0}$ & $\mathbf{7 0}$ & $\mathbf{8 0}$ & $\mathbf{9 0}$ & $\mathbf{1 0 0}$ \\
\hline Far-reaching planning horizons of port master plans & & & & & & & & & \\
\hline Terminal and port superstructure & & & & & & & & & & \\
\hline Pavements & & & & & & & & & \\
\hline Berth structures serving special industries & & & & & & & & \\
\hline Open piers (open piled structures) & & & & & & & & \\
\hline Dry docks & & & & & & & \\
\hline Shore protection works & & & & & & \\
\hline Quay walls & & & & & & & \\
\hline Flood protection & & & & & & \\
\hline Breakwaters & & & & & & \\
\hline
\end{tabular}

Seaport infrastructure in general is characterized by long life spans, enforcing long-term planning horizons. Climate change issues may impact the construction and operation of seaports in manifold ways, with respect to navigation water levels, overhead clearances, sedimentation patterns, structural loads, material deterioration, etc. Therefore, early involvement of climate change aspects, especially in port planning processes of long living assets, is highly recommended. 
In the following, a method is described to assess climate change vulnerability of seaports and possible adaptation measures are explained. Further information on the issue will be provided by the PIANC guideline of Working Group 178 currently under development and planned to be published until end of 2017.

\section{Climate change vulnerability of seaports}

Vulnerability can be described by three components: exposure, sensitivity and adaptation capacity. By combination of the findings of this three-step analysis the vulnerability of the relevant seaport to climate change impacts can be assessed.

The determination of the exposure of a specific port has to be based on an analysis of relevant climate parameters on-site and expected climate change impacts on a regional scale, whereas climate change phenomena bear risks but in some cases also opportunities for seaports. Often, a potential worsening or improvement of the situation can only be assessed in a case-by-case manner. For example, changes in the wind direction distribution may reduce or increase wave load at breakwaters and jetties as well as within port basins. Furthermore, a change of one parameter due to climate change may also result in changes of other parameters not directly linked to climate change impacts. For example, rising mean sea level may change the tidal regime in estuaries. Often quite complex process chains have to be considered in the assessment of climate change impacts.

The aspects listed in Table 2 have to be examined within a sensitivity analysis and the issues listed in Table 3 have to be addressed in an adaptive capacity analysis.

Table 2: Aspects of a sensitivity analysis.

\begin{tabular}{|l|l|}
\hline 1. & System of interest, e.g. breakwater, quay wall, terminal infrastructure and superstructure, drainage system, etc. \\
\hline 2. & $\begin{array}{l}\text { System planning parameters, e.g. functional and structural design, operation characteristics, lifecycle aspects, } \\
\text { etc. }\end{array}$ \\
\hline 3. & $\begin{array}{l}\text { Current relevant climate conditions affecting the system in the planning area, e.g. storm surges, heavy } \\
\text { precipitation }\end{array}$ \\
\hline 4. & Existing stresses under current climate conditions, e.g. coastal erosion problems, high sedimentation rates \\
\hline 5. & Projected change of relevant climate conditions in the short-, mid- and long-term, e.g. sea level rise \\
\hline 6. & Projected impacts of climate change without preparedness action, e.g. increase of flood damages \\
\hline 7. & Degree of system sensitivity to climate change, e.g. high, moderate, low, uncertain \\
\hline
\end{tabular}


Mediterranean rocky coasts:

Features, processes, evolution and problems

Table 3: Issues of an adaptive capacity analysis.

\begin{tabular}{|l|l|}
\hline 1. & System of interest, e.g. breakwater, quay wall, terminal infrastructure and superstructure, drainage system, etc. \\
\hline 2. & $\begin{array}{l}\text { System planning parameters, e.g. functional and structural design, operation characteristics, lifecycle aspects, } \\
\text { etc. }\end{array}$ \\
\hline 3. & Ability of the system to cope with climate change effects \\
\hline 4. & $\begin{array}{l}\text { Obstacles to a system's ability to cope with climate change effects, } \\
-\quad \begin{array}{l}\text { Legal regulations, e.g. environmental regulations restricting required dredging works } \\
\text { Limited management flexibility due to a high number of competing requirements }\end{array} \\
\text { Limited management flexibility due to geographic situation, e.g. relocation not possible due to hilly } \\
\text { 5. hinterland }\end{array}$ \\
\hline 6. & \begin{tabular}{l} 
Existing stresses and constraints limiting the system ability to accommodate climate changes \\
\hline
\end{tabular} \\
\hline
\end{tabular}

\section{Climate change adaptation measures}

In general, the following four port asset categories can be distinguished:

- Basic port infrastructure like maritime access channel, port entrance, protective works and hinterland connection

- Operational port infrastructure like inner port channels and port basins, quay walls and port internal traffic systems

- Port superstructure like pavements, drainage system, stacking areas, tank farms, silos, and warehouses

- Port equipment like ship and shore handling equipment as well as cargo handling and storage equipment

In the following, some general remarks will be given on adaptation measures for the port assets maritime access channel as well as breakwaters and jetties. Further information on adaptation measures will be provided end of 2017 by the PIANC guidelines of Working Group 178 currently under development.

\subsection{Maritime access channel}

The design of the maritime access channel regarding length, width and trace is strongly dependent on the port location with respect to open sea, estuary or waters with large tidal range. Often, water depth in the port access channel is not sufficient for larger vessels entering the port and the required water depth has to be guaranteed by rock drilling and blasting or dredging (both investment and maintenance dredging) as well as supporting constructions like groins and training structures, the latter being mainly used in estuary ports. 
Mediterranean rocky coasts:

Features, processes, evolution and problems

In estuaries, climate change risks with respect to maritime access channels are expected mainly due to an increase in sedimentation and thus a decrease in water depth. Changes in sediment transport are generally difficult to predict and countermeasures may be designed rather in a reactive manner and hardly in advance. Shorter maintenance dredging intervals are the most common countermeasure. Depending on the result of detailed hydrologic and sedimentological investigations, the construction of training structures influencing currents might be useful.

The entrance channel of ports at the open sea is generally less vulnerable to climate change effects as sea level rise and resulting larger water depths bear more opportunities than risks.

\subsection{Breakwaters and jetties}

Breakwaters and jetties border the port basin and entrance from the sea or estuary serving as a protection against waves and currents. In some cases, the inner side of the construction might be used as a berthing place. Depending on type, shape and transmissibility of a breakwater, wave forces, wave run-up and overtopping as well as wave transmission and reflection have to be assessed to determine the breakwater's height and layout. The latter should consider armor unit weight and layer thicknesses in case of rubble mound breakwaters and overall stability in case of vertical breakwaters.

As breakwaters are long-living and costly structures, the consideration of anticipated climate change effects is highly recommended in the design of new structures. Increasing wave loads have to be considered in the determination of armor unit weights of sloped constructions or component weight and stability of vertical constructions. It is recommended to conduct a sensitivity analysis of incident wave height and period dependent on wave direction to check if possible changes in the wind direction distribution may lead to a significant increase of wave load in the port entrance and at terminals. In addition, rising water levels have to be encountered by heightening the crest level or by arrangements offering a later heightening of the crest level, like wider bases and stronger foundations.

\section{Conclusions}

Subsequent to the definition of exposure to climate change a sensitivity analysis and an adaptive capacity analysis have to be conducted for the port as a whole and/ or for particular port assets. The combination of the findings of these analyses will result in a quantification of the vulnerability of the seaport to climate change impacts.

Adaptation measures in seaports with respect to climate change can be distinguished in active and reactive measures. Active measures are the appropriate solution for climate change sensitive port assets in case their expected lifetimes are long and a later 
Mediterranean rocky coasts:

Features, processes, evolution and problems

adaptation to climate change impacts may be connected with a significant increase in costs, e.g. in case of breakwater and flood protection design. But measures can also be executed in a reactive way, if this will lead to no significant increases in operational risks and costs. An example for a reactive measure is the shortening of maintenance dredging intervals in case an intensification of sedimentation in harbour entrance channels is observed. 